\title{
In situ androgen producing enzymes in human prostate cancer
}

\author{
Yasuhiro Nakamura ${ }^{1,2}$, Takashi Suzuki ${ }^{1}$, Masao Nakabayashi, \\ Mareyuki Endoh', Kazuhiro Sakamoto', Yoshiki Mikami ', Takuya Moriya', \\ Akihiro Ito ${ }^{3}$, Shoki Takahashi ${ }^{2}$, Shogo Yamada ${ }^{2}$, Yoichi Arai $^{3}$ and \\ Hironobu Sasano ${ }^{1}$
}

Departments of ${ }^{1}$ Pathology, ${ }^{2}$ Radiology, and ${ }^{3}$ Urology, Tohoku University School of Medicine, 2-1 Seiryo-machi, Aoba-ku, Sendai, 980-8575 Japan

(Requests for offprints should be addressed to Y Nakamura; Email: nakamura@patholo2.med.tohoku.ac.jp)

\begin{abstract}
Androgens have been proposed to be actively produced in situ in human prostate cancer. These locally produced androgens have also been considered to play important roles in the pathogenesis and development of prostate cancer. Therefore, it is important to examine the status of this in situ androgen metabolism and/or synthesis in detail in order to improve the clinical response to hormonal therapy in patients diagnosed with prostate cancer. Several studies have previously demonstrated the expression of androgen-producing enzymes such as $5 \alpha$-reductase types 1 and 2 , and $17 \beta$-hydroxysteroid dehydrogenase type 5 (17ß-HSD5), in human prostate carcinoma cells. However, their biological significance has remained largely unknown. In this study, we evaluated the immunoreactivities of these steroidogenic enzymes in human prostate cancer obtained from surgery $(n=70)$, and correlated the findings with clinicopathological features of the patients. 17 $\beta$-HSD5

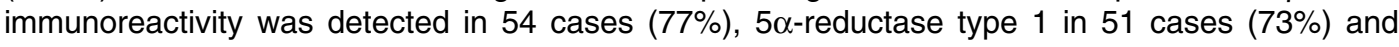
$5 \alpha$-reductase type 2 in 39 cases (56\%). $5 \alpha$-reductase type 2 immunoreactivity was significantly correlated with that of androgen receptor (AR), and 17ß-HSD5 positive cases were significantly associated with clinical stage (TNM stage pT3 vs pT2). These data all suggest that androgenproducing enzymes, such as $5 \alpha$-reductase type 1 and type 2 , and $17 \beta-H S D 5$ are expressed in a majority of prostate cancers, and are involved in the local production and actions of androgens in prostate cancers.
\end{abstract}

Endocrine-Related Cancer (2005) 12 101-107

\section{Introduction}

Androgens play important roles in the pathogenesis of prostate cancer (Lopez-Otin \& Diamandis 1998). In addition, the in situ production of androgens has been proposed to play a critical role in the pathogenesis and/ or development of human prostate cancer (Lopez-Otin \& Diamandis 1998). Moreover, suppression of androgen secretion and/or a blockade of their actions represent the basis for many forms of effective hormonal treatment of patients diagnosed with prostate cancer (Negri-Cesi et al. 1998). Therefore, it is very important to examine the status of expression of androgen metabolizing and/or producing enzymes in prostate cancer patients in order to obtain a better understanding of the possible roles of in situ androgen production and its action.
Testosterone, the main circulating androgen, is converted in prostate cancer tissues by $5 \alpha$-reductases into the bioactive and potent androgen, $5 \alpha$-dihydrotestosterone (DHT) (Russell \& Wilson 1994). Therefore, $5 \alpha$-reductases are considered to play important roles as local regulators of androgen and other sex steroid actions in prostate cancer tissues. The type 1 isozyme of $5 \alpha$-reductase is located on the distal short arm of chromosome 5, and is mainly expressed in the liver and skin (Thigpen et al. 1993, Russell \& Wilson 1994). The type 2 isozyme of $5 \alpha$-reductase is located in band p23 of chromosome 2, and is, in addition to its strong expression in the liver, also markedly expressed in the prostate, seminal vesicle, and epididymis (Thigpen et al. 1992, Thigpen et al. 1993). In a recent study by Dufort and co-workers, $17 \beta$-HSD5, which specifically catalyzes the reduction 
of androstenedione to testosterone, was cloned (Dufort et al. 1999). Several studies have previously demonstrated the presence of $5 \alpha$-reductase isozyme mRNAs and enzyme activities in human prostate carcinoma cells (Delos et al. 1998, Negri-Cesi et al. 1998, Soderstrom et al. 2002, Thomas et al. 2003). The mRNA for 17ß-HSD5 was also reported to be expressed in prostate cancer tissues (Koh et al. 2002). These findings indicate that in situ production of $5 \alpha$-dihydrotestosterone (DHT) from inactive androstenedione by $17 \beta$-HSD5 (reduction of androstenedione to testosterone), and via $5 \alpha$-reductase (metabolism of testosterone to DHT) in human prostate tissue may be occurring. However, the status of expression for these enzymes and their relation to clinicopathological findings has not been examined in human prostate cancer. Therefore, in this study, we first examined the immunolocalization of $5 \alpha$-reductase isozymes, and $17 \beta-H S D 5$ in human prostate carcinoma tissue specimens obtained from surgery. We then correlated these findings with various clinicopathological parameters of patients including the status of the androgen receptor (AR) in 70 cases of human prostate carcinoma in order to evaluate the possible roles of these androgen metabolizing/synthesizing enzymes in human prostate cancer.

\section{Materials and methods}

\section{Patients and tissues}

Seventy surgical pathology specimens of prostate carcinoma were obtained from patients who underwent prostatectomy from 1998-2003 at the Department of Urology, Tohoku University Hospital (Sendai, Japan). The mean age of the patients was 65.7 years (range: 48-77). All patients examined in this study did not receive radiation, chemotherapy, nor hormone therapy before surgery. Clinical data, including patient age, serum prostate specific antigen (PSA) concentration, clinical stage according to the International Union Against Cancer TNM classification (1987), lymph node status, and Gleason's score (Veltri et al. 1996) were retrieved from detailed patient charts describing individual patient histories. The histological grade of each tumor was evaluated by three of the authors (Y N, T S and H S). All specimens were fixed with $10 \%$ formalin and embedded in paraffin wax at the Department of Pathology, Tohoku University Hospital. The Ethic's Committee at Tohoku University School of Medicine approved the research protocol for this study.

\section{Antibodies}

$5 \alpha$-reductase type 1 and type 2 antibodies used in this study were rabbit polyclonal antibodies against synthesized peptides corresponding to amino acids 232-256 for $5 \alpha$-reductase type 1 , and amino acids $227-251$ for $5 \alpha$-reductase type 2 , respectively (Thigpen et al. 1993). These antibodies were kindly provided by Dr D W Russell (University of Texas Southwestern Medical Center, Dallas, TX). The polyclonal antibody for $17 \beta$-hydroxysteroid dehydrogenase type 5 (17 HSD5) was raised in a rabbit against a synthetic peptide corresponding to amino acids $297-320$ for $17 \beta$ HSD5 and was kindly provided by Dr V Luu (Laval University Hospital Center, Québec, Canada) (Pelletier et al. 1999). Characterization of these three antibodies was confirmed by immunoblotting, and the use of antibodies for $5 \alpha$-reductase type 2 and $17 \beta$-HSD 5 on immunohistochemistry has been previously reported (Thigpen et al. 1993, Silver et al. 1994, Pelletier et al. 1999). mAb against AR was purchased from DAKO Corporation (Carpinteria, CA).

\section{Immunohistochemistry}

Immunohistochemical analysis was performed employing the streptavidin-biotin amplification method using a Histofine Kit (Nichirei, Tokyo, Japan) and has been previously described in detail (Suzuki et al. 1994). For immunostaining of $\mathrm{AR}$, the slides were heated in an autoclave at $120^{\circ} \mathrm{C}$ for $5 \mathrm{~min}$ in citric acid buffer $(2 \mathrm{mmol} / 1$ citric acid and $9 \mathrm{mmol} / 1$ trisodium citrate dehydrate, $\mathrm{pH}$ 6.0) after deparaffinization for antigen retrieval. The dilutions of primary antibodies used in our study were as follows: $5 \alpha$-reductase type $1,1: 1000$; $5 \alpha$-reductase type 2, 1:1000; AR, 1:100; and 17 $\beta$ HSD5, $1: 1000$. The antigen-antibody complex was visualized with $3,3^{\prime}$-diaminobenzidine (DAB) solution [ $1 \mathrm{mmol} / 1 \quad 3,3^{\prime}$-DAB, $\quad 50 \mathrm{mmol} / 1$ Tris- $\mathrm{HCl}$ buffer ( $\mathrm{pH}$ 7.6), and $0.006 \% \mathrm{H}_{2} \mathrm{O}_{2}$ ] and counterstained with hematoxylin. Tissue sections of liver and prostate were used as positive controls for $5 \alpha$-reductase types 1 and 2 , respectively, and non-neoplastic breast tissue was used as a positive control for 17ß-HSD5 (Thigpen et al. 1993, Pelletier et al. 1999). As a negative control, normal rabbit or mouse $\operatorname{IgG}$ was used instead of the primary antibodies, and no specific immunoreactivity was detected in these reported tissue sections.

\section{Scoring of immunoreactivity}

Scoring of immunoreactivity was performed based on previous reports with some modifications (Soslow et al. 
2000, Suzuki et al. 2001). For statistical analyses of $5 \alpha-$ reductase type 1 and type 2, and 17ß-HSD5 immunoreactivity, the carcinoma cases were classified into the following two groups: + , positive, more than $10 \%$ positive cells; and -, no immunoreactivity, less than $10 \%$ positive cells according to Soslow and colleagues (Soslow et al. 2000). The evaluation (+, positive carcinoma cells; and -, no immunoreactivity) was performed by three of the authors (Y N, T S and H S), independently. Cases with discordant results among these investigators above were re-evaluated. Scoring of $\mathrm{AR}$ in carcinoma cells was performed on high power fields $(\times 400)$ using standard light microscopy. In each case, more than 500 carcinoma cells were counted independently by the three authors above, and the percentage of immunoreactivity, i.e. labeling index (LI), was determined (Suzuki et al. 2001). In the present study, interobserver differences were less than $5 \%$, and the mean of these three values was obtained. In addition, as a control, immunoreactivity for $5 \alpha$-reductase type 1 and 2, 17ß-HSD5, and AR was examined in the peripheral zone of non-neoplastic glands in each case.

\section{Statistical analysis}

Values for patient age, serum PSA levels, and LI for AR were presented as the mean $\pm 95 \%$ confidence interval $(95 \% \mathrm{CI})$, and associations between $5 \alpha-$ reductase immunoreactivity and the parameters described above were evaluated using the Bonferroni test. Statistical differences between immunoreactivity for $5 \alpha$-reductases and stage, lymph node status, histological grade, and immunoreactivity for $17 \beta$-HSD5, were evaluated in a cross-table using the $\chi^{2}$-test. $P<0.05$ was considered significant.

\section{Results}

\section{Immunohistochemistry}

Immunoreactivity for $5 \alpha$-reductase type 1 and type 2, and 173-HSD5 was detected in the cytoplasm of carcinoma cells, whereas AR immunoreactivity was detected in the nuclei of carcinoma cells (Fig. 1A-D). In the non-neoplastic peripheral zone, immunoreactivity for $5 \alpha$-reductase type $2,17 \beta-\mathrm{HSD} 5$, and AR was detected in the glandular epithelium, but
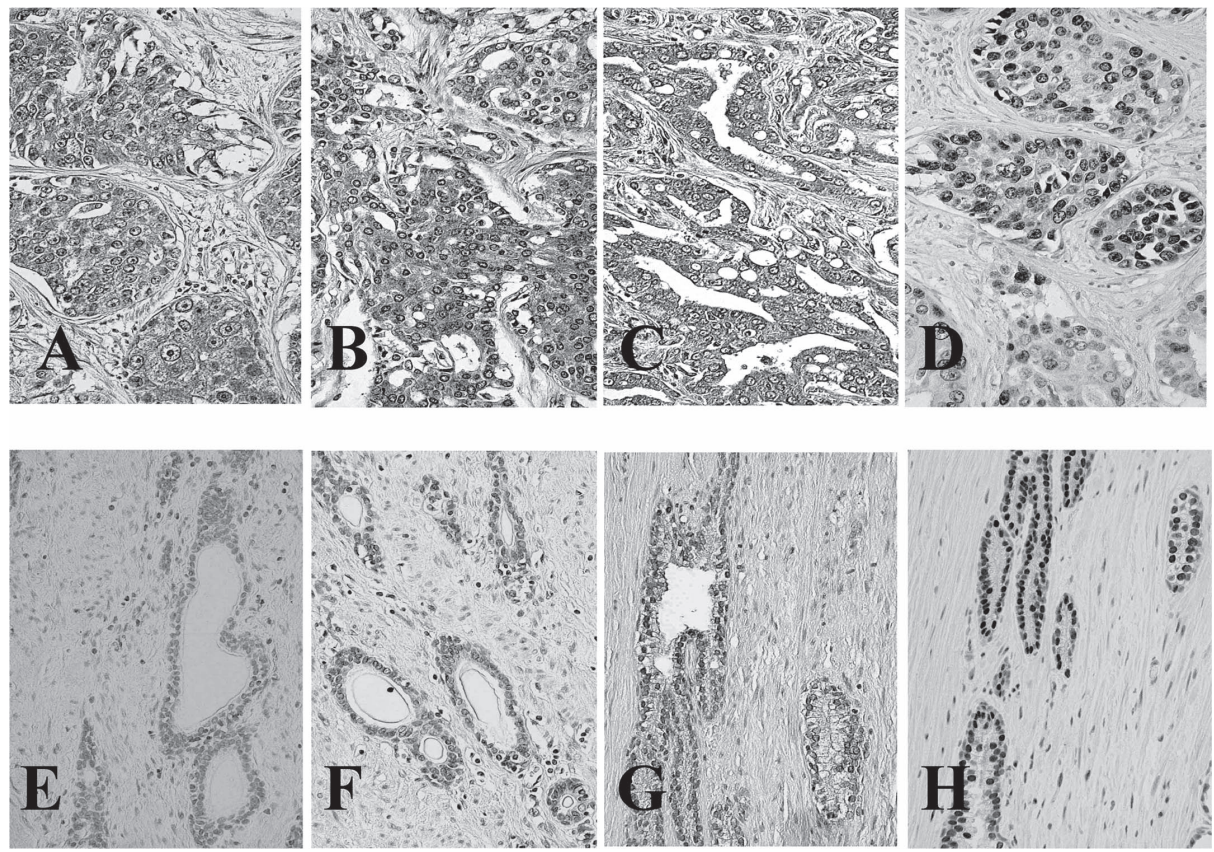

Figure 1 Immunohistochemistry of $5 \alpha$-reductase type $1(A)$ and type $2(B), 17 \beta-H S D 5(C)$, and AR (D) in human prostate carcinoma, and immunohistochemistry of $5 \alpha$-reductase type $1(E)$ and type $2(F), 17 \beta-H S D 5(G)$, and AR (H) in non-neoplastic glands of the peripheral zone of human prostate. Immunoreactivity of $5 \alpha$-reductase type 1 (A) and type 2 (B), 17 $\beta$-HSD5 (C) was detected in the cytoplasm of carcinoma cells, whereas that of AR (D) was detected in the nucleus of carcinoma cells. In addition, immunoreactivity of $5 \alpha$-reductase type $2(F)$, and $17 \beta-H S D 5(G)$ was detected in the cytoplasm of non-neoplastic glands of the peripheral zone, whereas that of $A R(H)$ was detected in the nucleus of non-neoplastic glands of the peripheral zone. However, immunoreactivity of $5 \alpha$-reductase type 1 (E) was not detected. Original magnification, $\times 400$. 
Table 1 Correlation among $5 \alpha$-reductases immunoreactivity and $17 \beta$-HSD type 5 immunoreactivity in human prostate cancer

\begin{tabular}{ll}
\hline & $P$ value \\
\hline $5 \alpha$-reductase type 1 and $5 \alpha$-reductase type 2 & $0.0004^{*}$ \\
$5 \alpha$-reductase type 1 and $17 \beta$-HSD type 5 & 0.0993 \\
$5 \alpha$-reductase type 2 and $17 \beta$-HSD type 5 & $0.0049^{*}$ \\
\hline
\end{tabular}

${ }^{*} P<0.05$.

$5 \alpha$-reductase type 1 immunoreactivity was negative in this study (Fig. 1E-H). The number of positive cases and their corresponding percentages were as follows: $51 / 70(73 \%)$ for $5 \alpha$-reductase type $1,39 / 70$ cases $(56 \%)$ for $5 \alpha$-reductase type 2 , and $54 / 70$ cases $(77 \%)$ for 17ß-HSD5.

\section{Correlation among $5 \alpha$-reductases and 17 $\beta$-HSD5 immunoreactivity}

A statistically significant positive correlation was detected between $5 \alpha$-reductase type 1 and type 2 immunoreactivity $(P=0.0004)$, and between $5 \alpha$-reductase type 2 and 17 3 -HSD5 immunoreactivity $(P=0.0049)$ (Table 1) A similar trend was also detected between $5 \alpha$-reductase type 1 and $17 \beta$-HSD5 immunoreactivity, but the correlation did not reach statistical significance $(P=0.0993)$ (Table 1$)$.

\section{Correlation between immunoreactivities and clinicopathological parameters}

Immunoreactivity for $5 \alpha$-reductase type 1 was not significantly correlated with clinicopathological parameters including patient age, concentration of serum

Table 2 Correlation between $5 \alpha$-reductase type 1 immunoreactivity and clinicopathological parameters in human prostate cancer

\begin{tabular}{lccc}
\hline & $+(\mathrm{n}=\mathbf{5 1})$ & $-(n=\mathbf{1 9})$ & $\boldsymbol{P}$ value \\
\hline Age (years) & $65.2 \pm 0.9$ & $66.6 \pm 1.3$ & 0.3851 \\
PSA (ng/ml) & $14.0 \pm 1.8$ & $17.2 \pm 4.0$ & 0.6540 \\
Gleason score & & & \\
$\quad 2-6$ & $8(11.4 \%)$ & $5(7.1 \%)$ & \\
7 & $22(31.4 \%)$ & $10(14.3 \%)$ & 0.2612 \\
$\quad 8-10$ & $21(30.0 \%)$ & $4(5.7 \%)$ & \\
Stage & & & \\
$\quad$ pT2 & $20(28.6 \%)$ & $9(12.9 \%)$ & \\
$\quad$ pT3 & $31(44.3 \%)$ & $10(14.3 \%)$ & 0.5380 \\
Lymph node status & & & \\
$\quad+$ & $6(8.6 \%)$ & $2(2.9 \%)$ & \\
$\quad-$ & $45(64.3 \%)$ & $17(24.3 \%)$ & 0.0849 \\
AR LI (\%) & $68.1 \pm 3.2$ & $69.1 \pm 4.0$ & 0.8703 \\
\hline
\end{tabular}

Table 3 Correlation between $5 \alpha$-reductase type 2 immunoreactivity and clinicopathological parameters in human prostate cancer

\begin{tabular}{lccc}
\hline & $+(\mathrm{n}=\mathbf{3 9})$ & $-(\mathrm{n}=\mathbf{3 1})$ & $\boldsymbol{P}$ value \\
\hline Age (years) & $65.3 \pm 1.1$ & $66.0 \pm 0.9$ & 0.6203 \\
PSA (ng/ml) & $13.5 \pm 1.9$ & $17.0 \pm 3.3$ & 0.4390 \\
Gleason score & & & \\
$\quad 2-6$ & $6(8.6 \%)$ & $7(10.0 \%)$ & \\
7 & $19(27.1 \%)$ & $13(18.6 \%)$ & 0.7203 \\
$\quad 8-10$ & $14(20.0 \%)$ & $11(15.7 \%)$ & \\
Stage & & & \\
$\quad$ pT2 & & & \\
$\quad$ pT3 & $14(20.0 \%)$ & $15(21.4 \%)$ & \\
Lymph node status & $25(35.7 \%)$ & $16(22.9 \%)$ & 0.2920 \\
$\quad+$ & $3(4.3 \%)$ & $5(7.1 \%)$ & \\
$\quad-$ & $36(51.4 \%)$ & $26(37.1 \%)$ & 0.2704 \\
AR LI (\%) & $73.4 \pm 3.1$ & $62.1 \pm 4.0$ & $0.0281^{*}$ \\
\hline
\end{tabular}

*Data was considered significant.

PSA levels, Gleason's score, pT stage, lymph node states, and AR LI (Table 2) There was a statistically positive correlation between $5 \alpha$-reductase type 2 immunoreactivity and AR LI $(P=0.0281)$ (Table 3), however, it was not significantly correlated with other clinicopathological parameters (Table 3 ).

$17 \beta$-HSD5 immunoreactivity was significantly associated with clinical stage in this study (TNM stage pT3 vs pT2) $(P=0.0115)$ (Table 4$)$

\section{Discussion}

It is well known that androgens play important roles in the pathogenesis of prostate cancer (Lopez-Otin \&

Table 4 Correlation between 17ß-HSD type 5 immunoreactivity and clinicopathological parameters in human prostate cancer

\begin{tabular}{lrcc}
\hline & $+(\mathrm{n}=\mathbf{5 4})$ & $-(\mathrm{n}=\mathbf{1 6})$ & $\boldsymbol{P}$ value \\
\hline Age (years) & $65.5 \pm 0.9$ & $65.8 \pm 1.1$ & 0.8716 \\
PSA (ng/ml) & $14.7 \pm 1.7$ & $13.8 \pm 6.2$ & 0.6204 \\
Gleason score & & & \\
$\quad 2-6$ & $8(11.4 \%)$ & $5(7.1 \%)$ & \\
7 & $25(35.7 \%)$ & $7(10.0 \%)$ & 0.2895 \\
$\quad 8-10$ & $21(30.0 \%)$ & $4(5.7 \%)$ & \\
Stage & & & \\
$\quad$ pT2 & $18(25.7 \%)$ & $11(15.7 \%)$ & \\
$\quad$ pT3 & $36(51.4 \%)$ & $5(7.1 \%)$ & $0.0115^{\star}$ \\
Lymph node status & & & \\
$\quad+$ & $7(10.0 \%)$ & $1(1.4 \%)$ & \\
$\quad-$ & $47(67.1 \%)$ & $15(21.5 \%)$ & 0.4585 \\
AR LI(\%) & $69.4 \pm 2.8$ & $64.8 \pm 6.1$ & 0.4572 \\
\hline
\end{tabular}

*Data was considered significant. 
Diamandis 1998). Although plasma concentrations of testosterone have been shown to decrease more than $90 \%$ following castration, androgen levels in prostate cancer tissues decreased only $50-60 \%$, suggesting the importance of in situ androgen production in prostate cancers (Labrie 1991, Mizokami et al. 2004). Results from our present study suggest that androgen-producing enzymes are co-expressed in human prostate cancers, and involved in the local production of DHT, which may play important roles in biological behavior of prostate carcinoma cells.

In the present study, the number of cases positive for steroidogenic enzymes and the corresponding percentages was $39 / 70$ cases $(56 \%)$ for $5 \alpha$-reductase type 2 . In addition, there was a statistically significant positive correlation between $5 \alpha$-reductase type 2 immunoreactivity and AR LI. It has been reported that type $25 \alpha$-reductase was expressed in prostate cancer, and was very important in the process of in situ production of DHT (Torres et al. 2003). In addition, type $25 \alpha$-reductase has been also hypothesized to play a role in the pathogenesis and/or development of prostate cancer (Torres et al. 2003). Moreover, it has also been reported that men who have had some polymorphism of the type $25 \alpha$-reductase gene have a significantly increased risk of prostate cancer development and/or progression (Nam et al. 2001). Our data are consistent with these reports, and suggest that $5 \alpha$-reductase type 2 may play an important role in the in situ production and action of DHT in human prostate cancer tissues.

Results from the present study also demonstrated that $5 \alpha$-reductase type 1 was frequently expressed in human prostate cancer $(73 \%)$. In addition, we demonstrated that a significant positive correlation was demonstrated between $5 \alpha$-reductase type 1 and type 2 immunoreactivity. It has been suggested that individuals with greater $5 \alpha$-reductase are at an increased risk for developing prostate cancer. Furthermore, previous reports have demonstrated that type 1 $5 \alpha$-reductase mRNA and activity were much greater in prostate cancers than in benign prostate tissues (Steers 2001, Iehle et al. 1999). These data suggest that both type 1 and type $25 \alpha$-reductases are likely to be important in the local production and action of DHT in human prostate cancer. It has also been reported that treatment of finasteride, a $5 \alpha$-reductase type 2 inhibitor, to patients diagnosed with metastatic prostate cancer resulted in only minor effects in this cancer (Presti et al. 1992), and decreased serum PSA levels by only $7 \%$ in men with advanced adenocarcinoma of the prostate (Brufsky et al. 1997). In contrast, however, dutasteride, which inhibits both type 1 and type 2
$5 \alpha$-reductases, treatment has recently been reported to result in almost complete suppression of intraprostatic DHT, and increased regression of prostate cancer (Andriole et al. 2004). Results from these studies suggest that $5 \alpha$-reductase type 1 , as well as the type 2 isozyme, are associated with the growth of prostate cancer. Furthermore, knowing the expression pattern and profile of $5 \alpha$-reductase isozymes may be important when considering the use of $5 \alpha$-reductase inhibitors in reducing the progression of prostate carcinoma in patients diagnosed with this aggressive cancer via the inhibition of in situ DHT production. However, further investigations are required to clarify the role of $5 \alpha$-reductase isozymes and related steroidogenic enzymes in the pathogenesis of prostrate carcinoma.

Iehle and colleagues demonstrated that $5 \alpha$-reductase type $1 \mathrm{mRNA}$ is abundantly expressed in the epithelial cells of normal prostate, whereas stromal cells of this glandular tissue demonstrated greatly reduced levels (Iehle et al. 1999). In our study, we could not identify significant immunoreactivity of $5 \alpha$-reductase type 1 in the non-neoplastic peripheral zone of the prostate. A previous study also demonstrated that type 1 $5 \alpha$-reductase mRNA and activity were much lower in benign prostate tissues than in prostate cancers (Steers 2001). Therefore, protein expression levels of $5 \alpha$-reductase type 1 in non-neoplastic areas of the human prostate were considered below the limits of detection by immunohistochemistry.

In the present study, 17 $\beta$-HSD5 immunoreactivity was detected in carcinoma cells of $77 \%$ of prostate cancer tissues, and was positively associated with clinical stage $(P<0.05$; TNM stage III vs TNM stage II). It is well-known that cell proliferation in the normal prostate and in prostate cancer is mainly controlled by testosterone following intracellular conversion to DHT (Ross \& Henderson 1994, ImperatoMcGinley et al. 1992). However, it has also been demonstrated that the remodeling of prostate stromal tissue via testosterone may play a role in the early stage of prostate carcinogenesis, which is generally considered to be favorable for tumor development ( $\mathrm{Li}$ et al. 2001). Therefore, 17 $\beta$-HSD5 may be involved in increasing the local concentration of testosterone in prostate cancer tissues, resulting in the progression, invasion, and further development of prostate cancer.

In summary, we have demonstrated that $5 \alpha$-reductase types 1 and 2, and 17 $\beta$-HSD5 were all detected in the great majority of prostate cancer tissues, and significant positive association was detected between $5 \alpha$-reductase types 2 and AR and/or 17 $\beta$-HSD5 and clinical stage. These data also indicate the importance of these androgen metabolizing/synthesizing enzymes 
in the local production and action of androgens in human prostate cancer.

\section{References}

Andriole GL, Humphrey P, Ray P, Gleave ME, Trachtenberg J, Thomas LN, Lazier CB \& Rittmaster RS 2004 Effect of the dual 5alpha-reductase inhibitor dutasteride on markers of tumor regression in prostate cancer. Journal of Urology 172 915-919.

Brown CT \& Nuttall MC 2003 Dutasteride: a new 5-alpha reductase inhibitor for men with lower urinary tract symptoms secondary to benign prostatic hyperplasia. International Journal of Clinical Practice 57 705-709.

Brufsky A, Fontaine-Rothe P, Berlane K, Rieker P, Jiroutek M, Kaplan I, Kaufman D \& Kantoff P 1997 Finasteride and flutamide as potency-sparing androgen-ablative therapy for advanced adenocarcinoma of the prostate. Urology 49 913-920.

Delos S, Carsol JL, Fina F, Raynaud JP \& Martin PM 1998 5alpha-reductase and 17ß-hydroxysteroid dehydrogenase expression in epithelial cells from hyperplastic and malignant human prostate. International Journal of Cancer 75 840-846.

Dufort I, Rheault P, Huang XF, Soucy P \& Luu-The V 1999 Characteristics of a highly labile human type $517 \beta$ hydroxysteroid dehydrogenase. Endocrinology 140 568-574.

Iehle C, Radvanyi F, Gil Diez de Medina S, Ouafik LH, Gerard H, Chopin D, Raynaud JP \& Martin PM 1999 Differences in steroid 5alpha-reductase iso-enzymes expression between normal and pathological human prostate tissue. Journal of Steroid Biochemistry and Molecular Biology 68 189-195.

Imperato-McGinley J, Gautier T, Zirinsky K, Hom T, Palomo O, Stein E, Vaughan ED, Markisz JA, Ramirez de tArellano E \& Kazam E 1992 Prostate visualization studies in males homozygous and heterozygous for 5 alpha-reductase deficiency. Journal of Clinical Endocrinology and Metabolism 75 1022-1026.

Koh E, Noda T, Kanaya J \& Namiki M 2002 Differential expression of $17 \beta$-hydroxysteroid dehydrogenase isozyme genes in prostate cancer and noncancer tissues. Prostate 53 154-159.

Labrie F 1991 Endocrine therapy for prostate cancer. Endocrinology and Metabolism Clinics of North America 20 845-872.

Li SC, Chen GF, Chan PS, Choi HL, Ho SM \& Chan FL 2001 Altered expression of extracellular matrix and proteinases in Noble rat prostate gland after long-term treatment with sex steroids. Prostate 49 58-71.

Lopez-Otin C \& Diamandis EP 1998 Breast and prostate cancer: an analysis of common epidemiological, genetic, and biochemical features. Endocrine Reviews 19 365-396.

Mizokami A, Koh E, Fujita H, Maeda Y, Egawa M, Koshida K, Honma S, Keller ET \& Namiki M 2004 The adrenal androgen androstenediol is present in prostate cancer tissue after androgen deprivation therapy and activates mutated androgen receptor. Cancer Research $\mathbf{6 4}$ 765-771.

Nam RK, Toi A, Vesprini D, Ho M, Chu W, Harvie S, Sweet J, Trachtenberg J, Jewett MA \& Narod SA 2001 V89L polymorphism of type-2, 5-alpha reductase enzyme gene predicts prostate cancer presence and progression. Urology 57 199-204.

Negri-Cesi P, Poletti A, Colciago A, Magni P, Martini P \& Motta M 1998 Presence of 5alpha-reductase isozymes and aromatase in human prostate cancer cells and in benign prostate hyperplastic tissue. Prostate 34 283-291.

O'Leary MP, Roehrborn C, Andriole G, Nickel C, Boyle P \& Hofner K 2003 Improvements in benign prostatic hyperplasia-specific quality of life with dutasteride, the novel dual 5alpha-reductase inhibitor. BJU International 92 262-266.

Pelletier G, Luu-The V, Tetu B \& Labrie F 1999 Immunocytochemical localization of type $517 \beta-$ hydroxysteroid dehydrogenase in human reproductive tissues. Journal of Histochemistry and Cytochemistry $\mathbf{4 7}$ 731-738.

Presti JC Jr, Fair WR, Andriole G, Sogani PC, Seidmon EJ, Ferguson D, Ng J \& Gormley GJ 1992 Multicenter, randomized, double-blind, placebo controlled study to investigate the effect of finasteride (MK-906) on stage D prostate cancer. Journal of Urology 148 1201-1204.

Ross RK \& Henderson BE 1994 Do diet and androgens alter prostate cancer risk via a common etiologic pathway? Journal of the National Cancer Institute 86 252-254.

Russell DW \& Wilson JD 1994 Steroid $5 \alpha$-reductase: two genes/two enzymes. Annual Reviews of Biochemistry $\mathbf{6 3}$ 25-61.

Silver RI, Wiley EL, Thigpen AE, Guileyardo JM, McConnell JD \& Russell DW 1994 Cell type specific expression of steroid $5 \alpha$-reductase 2. Journal of Urology $152438-442$.

Soderstrom T, Wadelius M, Andersson SO, Johansson JE, Johansson S, Granath F \& Rane A 2002 5alpha-reductase 2 polymorphisms as risk factors in prostate cancer. Pharmacogenetics 12 307-312.

Soslow RA, Dannenberg AJ, Rush D, Woerner BM, Khan KN, Masferrer J \& Koki AT 2000 COX-2 is expressed in human pulmonary, colonic, and mammary tumors. Cancer 89 2637-2645.

Steers WD 2001 5alpha-reductase activity in the prostate. Urology 58 17-24.

Suzuki T, Darnel AD, Akahira JI, Ariga N, Ogawa S, Kaneko C, Takeyama J, Moriya T \& Sasano H 2001 5alpha-reductases in human breast carcinoma: possible modulator of in situ androgenic actions. Journal of Clinical Endocrinology and Metabolism 86 2250-2257.

Suzuki T, Sasano H, Kimura N, Tamura M, Fukaya T, Yajima A \& Nagura H 1994 Immunohistochemical distribution of progesterone, androgen and oestrogen receptors in the human ovary during the menstrual 
cycle: relationship to expression of steroidogenic enzymes. Human Reproduction 9 1589-1595.

Thigpen AE, Davis DL, Milatovich A, Mendonca BB, Imperato-McGinley J, Griffin JE, Francke U, Wilson JD \& Russell DW 1992 Molecular genetics of steroid $5 \alpha$ reductase 2 deficiency. Journal of Clinical Investigation 90 799-809.

Thigpen AE, Silver RI, Guileyardo JM, Casey ML, McConnell JD \& Russell DW 1993 Tissue distribution and ontogeny of steroid 5 alpha-reductase isozyme expression. Journal of Clinical Investigation 92 903-910.

Thomas LN, Douglas RC, Vessey JP, Gupta R, Fontaine D, Norman RW, Thompson IM, Troyer DA, Rittmaster RS
\& Lazier CB 2003 5alpha-reductase type 1 immunostaining is enhanced in some prostate cancers compared with benign prostatic hyperplasia epithelium. Journal of Urology 170 2019-2025.

Torres JM, Ruiz E \& Ortega E 2003 Development of a quantitative RT-PCR method to study 5alpha-reductase mRNA isozymes in rat prostate in different androgen status. Prostate 56 74-79.

Veltri RW, Miller MC, Partin AW, Coffey DS \& Epstein JI 1996 Ability to predict biochemical progression using Gleason score and a computer-generated quantitative nuclear grade derived from cancer cell nuclei. Urology 48 685-691. 
